\title{
Mentorship provision for student nurses: Conceptions of Finnish and British mentors in healthcare placements
}

\author{
Merja J okelainen ${ }^{1}$, David J amookeeah ${ }^{2}$, Kerttu Tossavainen ${ }^{1}$, Hannele Turunen ${ }^{1}$ \\ 1. Department of Nursing Science, University of Eastern Finland, Kuopio, Finland. 2. School of Health, University of \\ Bradford, Bradford, UK.
}

Correspondence: Merja Jokelainen. Address: Department of Nursing Science, University of Eastern Finland, P.O. Box 1627, 70211 Kuopio, Finland. Telephone: 35-850-526-8619. Email: merja.jokelainen@savonia.fi.

Received: May 31, 2012

Accepted: June 10, $2012 \quad$ Published: February 1, 2013

DOI : $10.5430 /$ jnep.v3n2p41

URL: http://dx.doi.org/10.5430/jnep.v3n2p41

\section{Abstract}

Background: The unification process for clinical education in Europe seeks to standardise the attainment of competencies by students and effective mentorship is central to this.

Aim: This paper is a report on a study describing Finnish and British mentors' conceptions of mentorship provision for pre-registration nursing students during placement learning in healthcare settings.

Methods: This qualitative study adopted a phenomenographical approach, which focused on the different ways mentorship provision for student nurses were experienced. Conceptions data from Finnish $(n=22)$ and British $(n=17)$ mentors were collected from nine focus group interviews between 2007 and 2008.

Findings: The mentors' conceptions consisted of dimensions of organisational, environmental, educational and personal provisions, which connected to three categories of description: workable, insufficient and improvement-requiring mentorship. The workable student mentorship included efficient organisations, well-equipped learning environments, co-operative partnerships and the mentors' personal and professional competence. The insufficient student mentorship was characterised by deficient managerial investments, overloaded placements with stressed staff, unsatisfying co-operation with stakeholders and lack of resources and personal skills of mentors. The improvement-requiring mentorship emphasized higher status and clearer guidelines for mentorship, appropriate placement allocation with joint involvement of stakeholders, better level of student preparedness, and more educational and personal resources for mentors.

Conclusion: There is a need to create a systematic, collaborative and highly valued strategy for mentorship provision for pre-registration nursing students in the healthcare settings. This would increase the quality of placement learning, enhance recruitment of the nursing workforce and also harmonise clinical education in Europe.

\section{Key words}

Mentorship, Nursing, Phenomenography, Pre-registration nursing education, Student nurses 


\section{Introduction}

Nursing education is a part of the higher education offered in pre-registration programmes of degree level in many European countries. These nursing degree programmes provided by higher education institutions (HEIs) ensure pre-registration student nurses to acquire the competencies needed for formal graduation as a registered nurse (RN) according to the directives of the European Union (EU) ${ }^{[1]}$. Pre-registration nursing education includes both the theoretical and practice components with academic status. To integrate the theoretical and practice-based learning components of nursing education requires different structures, systems and approaches ${ }^{[2]}$. Finland and United Kingdom (UK) as members of the EU have similar principles of theoretical and clinical nursing education in line with the EU directives. The academic level is equal, but the duration of nursing programme varies; in the UK it takes three years, whereas in Finland three and half years ${ }^{[3]}$.

The European Council recommends that the clinical practice component should comprise $50 \%$ of the nursing education programme and take place in healthcare settings ${ }^{[4]}$. This already occurs in the UK in line with the requirements of the Nursing and Midwifery Council (NMC) ${ }^{[1]}$. Whereas in Finland the nursing degree programme comprises about 38\% practice learning ${ }^{[5,6]}$. Taylor et al. maintain that degree programmes tend to focus too closely on theoretical studies to the detriment of clinical practice ${ }^{[7]}$. Nevertheless, nursing education should embed and address the realities of nursing practice.

Many proposals for the unification of the clinical practice components of pre-registration healthcare education programmes have been made in Europe. For example, the Bologna Treaty called for the harmonisation of educational systems within the EU. The need for a comprehensive educational system, which integrates the academic and clinical competencies, has been established ${ }^{[3]}$. Furthermore, the unification of clinical education would enhance the employability and mobility of nursing students in Europe ${ }^{[8]}$. This will also increase the opportunities for exchange students to gain comparable and quality placements learning experiences in European countries. Equally importantly, a unified clinical education system will harmonise mentorship provision for healthcare students in Europe. This will lead to an equitably prepared healthcare workforce in Europe. In order to achieve this, new strategies and standards in nursing education have to be developed and implemented to ensure the competencies of newly qualified nurses ${ }^{[7]}$. In United Kingdom new standards for supporting learning and assessment in practice have been embedded in mentor preparation programmes ${ }^{[9]}$. This has lead to unified system of mentorship for pre-registration nursing and midwifery education. The need for this study was indicated in order to examine the quality of current mentorship provision from perspectives of a sample of Finnish and British mentors.

\section{Background}

Many changes in nursing education and its status in higher education in Europe have influenced placement learning provisions. Nursing has a strong practical element in spite of the academic demands of higher education ${ }^{[10]}$. In United Kingdom challenges regarding the types, capacity and quality of clinical placements offered have been reported. Insufficient and poor quality placements have to be reviewed and reformed ${ }^{[11]}$. The need to discover new approaches for integration and organization of the theoretical and practical components of nursing education programmes has been recommended ${ }^{[10]}$. For example, Taylor et al. presented various innovative strategies for the implementation of clinical learning ${ }^{[7]}$.

The clinical learning model for student nurses evolution from novice to proficient registered nurses introduces factors, which depended on the students themselves and the learning environments ${ }^{[12]}$. It was essential that students experienced a sense of being part of a team ${ }^{[13]}$, being respected and receiving support, feedback and assessment during placement learning ${ }^{[14]}$. Furthermore, clinical learning environments enhanced students' learning outcomes, where the ward atmosphere was considered the most significant element in placement learning ${ }^{[10]}$. Supportive and positive ward atmosphere will also influence students' attraction to the profession and the particular placement as a future workplace 
after graduation. Positive perceptions of nursing as a career will encourage young people to enter nursing education and to join the profession ${ }^{[7]}$.

The current challenges and pressures in nursing, such as inadequate budget, shortage of staff, new guidelines and standards and changes in care delivery can complicate the provision of quality clinical placement opportunity for student nurses ${ }^{[11]}$. It is, therefore, imperative for nursing and higher education institutions to work in partnership to ensure quality placement learning provision. However, it is essential that the placement learning component addresses the realities of current and future nursing practice in seeking to prepare competent nurses.

Student mentorship requires qualified and experienced nurses to act as mentors for individual students ${ }^{[1,5]}$. This role requires mentors to facilitate students' personal and professional growth and the development of nursing competencies. It has been presented that a mentor acts as a role model, guides and advises a student ${ }^{[14]}$. A mutual relationship between mentor and student is essential ${ }^{[3]}$. Mentors are also expected to facilitate a supportive learning environment and make assessment judgement about student's performance and attainment of clinical skills ${ }^{[15]}$. In Finland and in the UK student nurses have their clinical practice in placements under supervision with clinical nurses acting as mentors. In addition, the teacher from university supports students' clinical learning focusing mainly on liaison and evaluation. Usually students spend practice periods of one to three months in one clinical placement during semesters. In both countries the student nurses have a role of a learner in placements with the supernumerary status not being part of the workforce ${ }^{[3]}$.

Furthermore, it has been argued that mentors must be willing to mentor nursing students and need protected time to provide this effectively ${ }^{[14]}$. They should also be familiar with the nursing education programme ${ }^{[16]}$ and its objectives ${ }^{[14]}$. Previous studies have also suggested that the preparation of mentors and the collaboration of stakeholders involved are crucial. Such close co-operation between stakeholders, such as university teacher/educators, service managers and colleagues, is necessary ${ }^{[14]}$. In the UK the NMC requires all mentors to have successfully completed an approved mentor preparation programme ${ }^{[1]}$.

In many European countries mentorship is provided on a ratio one student to a mentor. This individualised approach is quite a common system ${ }^{[17]}$. It has been found that students with a personal mentor with a protected time for mentorship were more satisfied than students without this arrangement ${ }^{[3]}$. The mutual mentor-student relationship, however, has been problematic. Stakeholders involved in mentoring students during placement learning have different roles and expectations, which can make effective mentorship difficult ${ }^{[3]}$. However, it has been presented different approaches to the provision of mentoring nursing students during placement learning ${ }^{[6]}$.

\section{Method}

\subsection{Aim and design}

The aim of this study was to describe Finnish and British mentors' conceptions of current mentorship provision for pre-registration nursing students in healthcare placements. A qualitative research design with phenomenography approach was used to collect data during 2007 and 2008 using focus group interviews.

\subsection{Participants}

Mentors of nursing students from Finland ( $\mathrm{n}=22)$ and from the UK $(\mathrm{n}=17)$ participated in this study. Participating mentors worked in healthcare centres, homecare units and hospitals in the adult nursing branch. The hospitals were general, private or university hospitals, which included medical, surgical, emergency wards and outpatient clinics. Nearly all of the mentors were women (95\%) and they ranged from 29 to 58 years (mean age 43). The inclusion criterion was that a nurse/mentor should have been mentoring students for a minimum period of two years. Nearly half of mentors (46\%) had more than 15 years of mentoring experience. Most of the British mentors (88\%) had completed an approved mentor 
preparation programme, whereas $32 \%$ of the Finnish mentors had participated in voluntary educational programmes of varying lengths.

\subsection{Data collection}

The data was collected by means of focus group interviews conducted in Finland and United Kingdom. This approach was seen as an efficient way of gathering information about mentorship provision in the said countries. It also provided an insight into experiences, views and understanding of those involved in mentoring student nurses. The participants had the opportunity to discuss and share their personal thoughts, views and experiences of student mentorship ${ }^{[18]}$.

In Finland, voluntary mentors were asked to participate by ward managers, or mentors themselves contacted the researcher via e-mail. British mentors volunteered to participate in the study during their annual mentor updates. First 25 volunteered Finnish mentors were invited to focus groups, 22 attended. In the UK 17 British mentors took part in the focus group interviews, although first 20 voluntary mentors were invited. In Finland, a Finnish member of the research team conducted five focus group interviews comprising of four to five mentors at a time. Four focus group interviews were held in the UK, each comprising three to five mentors. These focus group interviews were conducted by a British member of the research team accompanied by two Finnish research team members. All interview sessions were audiotaped and these were held at the university or hospital settings during work shifts.

\subsection{Data analysis}

The data from all focus group interview sessions were transcribed by a person speaking the participants' native language. These data were analyzed via the phenomenographic approach, where the second-order perspective was the focus ${ }^{[19,20]}$. That is how mentors conceived the provision of nurse student mentorship in placements, not the first order perspective as singular essence of mentorship ${ }^{[19,20]}$. Firstly, the relevant data were reduced from mentors' different ways of experiencing the provision of current mentorship after familiarization and compilation of the empirical material. Next, the similarities and differences in these experiences were identified as the individual conceptions of mentors. After that, variations of these conceptions were grouped and sub-categories were created and named. In the next step, they were gathered into categories of description depending on the uniformity in descriptions in these sub-categories ${ }^{[20]}$.

In this study, the conceptions of mentors were formulated into three main categories of description with four sub-categories in each. The categories of description had equal value and they were in the same level horizontally. Furthermore, each four sub-categories and their conceptions in the vertical level had a same value. Each of these sub-categories consisted of similar attributes regarding the provision of different stakeholders, such as organisational, placement, educational and individual mentors’ procedures.

\subsection{Ethical considerations}

Ethical approvals were obtained from the Ethical Committees of Finnish and British institutions, which conducted this study. Mentors of student nurses from both countries were provided with an information sheet explaining the research aim and process before they expressed their willingness to participate in the study. The anonymity of participants in the focus groups was not been able to fully guaranteed, but the confidentiality was protected in the report ${ }^{\text {[21] }}$. All 39 mentors, who finally participated in the study, gave written informed consents.

\subsection{Trustworthiness of the study}

The trustworthiness has been considered in all phases of this study. For example, the data collection and data analysis have been presented clearly. The principal researcher reduced the data with deep insight and subsequently carried out a preliminary analysis and categorisation. The research team then reviewed the data analysis, confirming the validity of the categorisation. The validity of focus group interviews conducted in two countries was enhanced by native language speaking research member. Transcriptions of the data were carried out by Finnish and British nationals. The translation of Finnish data to English language was done by the principal researcher with help from members of the research team. 


\section{Findings}

The mentors' conception of provision of current student mentorship focused on three categories of description, which were workable, insufficient and improvement-requiring mentorship. They included four equal sub-categories with perspectives of organisational, placement, educational and individual mentors' procedures. The structure of the categories of description and their sub-categories has been presented in Table 1.

\subsection{Workable mentorship}

\subsubsection{Desirable and efficient organisations}

Mentors from both countries emphasised that the current student mentorship worked well and benefitted the organisation in the form of new staff placements. Also important was the system of a mentor with a co-mentor to provide a student adequate guidance as well as the co-operation of other stakeholders in the mentorship, such as clinical teachers or clinical placement facilitators. Both Finnish and British mentors felt that getting support from management, including head nurses, matrons or line managers, was crucial to creating a workable student mentorship system. Finnish mentors perceived the current student mentorship as "an old procedure”, because they did not have experiences of other systems. They also considered the nursing organisation as a financial investor of mentorship, because organisation receives money from the school to put into clinical education in placements. Furthermore, the Finnish mentors felt that opportunities to participate education during work time were also a workable practice in their organisation, while the British mentors highlighted the standards of student mentorship as a guaranteed system for future practitioners.

Maybe current mentorship is a good system because all our new substitutes are our ex-students. (Finnish mentor)

It is a good recruitment issue. It actually guarantees the standard for mentoring to future practitioners. (British mentor)

\subsubsection{Supportive and well-equipped learning environments}

More Finnish mentors than British mentors stated that placement procedures were also significant in student mentorship. They felt that if there was an atmosphere of collegiality in placement, it helped in student mentorship. However, both mentors lauded the support from each other, from their colleagues, team members and other working partners in placement. Finnish mentors also felt that a positive atmosphere in placement towards student mentorship is important in the current system. Furthermore, they introduced that common rules and proper staffing for sharing mentoring, allocating a suitable amount of incoming students, well-organised induction and the student feedback collection system were also crucial to successful mentorships. When having a workable mentorship, all practitioners in placements received benefits from students. They got fresh information, like new theoretical knowledge, computer skills and information retrieval skills.

It is good to have enough staff in placement, who can share mentorship. We all are very keen on mentoring students. (Finnish mentor)

Peer support is important. I have got support from my team and colleagues. (British mentor)

\subsubsection{Reciprocal and co-operative partnership with education}

One crucial procedure in the current student mentorship was having adequate support from educational stakeholders as lecturers, teachers and link persons. Mentors from both countries felt it is necessary to get support from students, especially in the form of their feedback, and support from the educational institutions when they have had difficulties in student mentorship situations. Finnish mentors have received support from the school through the educations of student 
mentorship. British mentors have participated mentor updates in order to know the new changes of nursing education. They also obtained new theoretical knowledge from teachers and students.

We get support from the school / university if we have problems. (Finnish and British mentors)

I have got support via participation in mentor education. (Finnish mentor)

I get support from lead lecture and mentor updates. You have got the theory side from university. (British mentor)

\subsubsection{Positive attitude and advanced professional competence of mentors}

Both Finnish and British mentors felt that their own professional development was a significant benefit in the student mentorship. They expressed that they learned new knowledge through the mentoring of students. In this manner, they built their own professional competencies. They also received professional support from their colleagues. Moreover, Finnish mentors emphasized that the mentorship works out well as long as mentors have positive attitudes toward their students. In addition, both Finnish and British mentors felt that a mentorship is workable when they receive positive and constructive feedback from students. Also, they felt that their own actions acted as recourse for student mentorship. Both Finnish and British mentors established that nurses' diverse ways of working and mentoring would be beneficial for students' learning.

Owing a personal positive attitude to successful student mentoring. (Finnish mentor)

The satisfaction from students actually does keep you going. (British mentor)

\subsection{I nsufficient mentorship}

\subsubsection{Unclear and deficient human and financial managerial investments}

Mentors' conceptions of insufficient mentorship focused on opposite procedures than in the first category. Both Finnish and British mentors felt that they had not received any support for their work from their organisation. In addition, Finnish mentors experienced that the role of clinical teachers was unclear and the support from their managers has been deficient. In return, their organisations still demanded that they keep flexible work schedules, for instance, coming off duty to participate in mentor education, because they did not have paid time set aside for mentor preparation programmes in their organisation. Furthermore, they argued that they received no compensation for their mentoring work. For example, they got no extra reward or education for student mentorship. The participation of mentor education changed neither the mentors' position or duty tasks in workplaces, nor their salary.

There is no support from our managers. (Finnish and British mentors)

Mentors get no extra remuneration. It would be some kind of support from the organisation. Although you have participated in mentor education it doesn't change anything. (Finnish mentor)

\subsubsection{Overloaded placements and stressed staff}

Both Finnish and British mentors emphasised that there were too many students in a single placement. In addition, Finnish mentors stated that mentorship was inadequate if there were not enough learning opportunities for students, or the placement restrictions have not been taken account. Also, the lack of collegial support in placement was also experienced by mentors in insufficient mentorship. British mentors still saw that hurry, work pressure and different work procedures in placements restrict the quality of student mentorship.

There are too many students in placements at the same time. (Finnish and British mentors) 
Your colleagues are so tired, they don't have any strength to help you with students. (Finnish mentor)

We got a lot of students. Therefore you have a lot of students because there are so few mentors. (British mentor)

\subsubsection{Disconnected perceptions and unsatisfying co-operation with education}

The lack of preliminary information from incoming students and their goals were seen also as inadequate student mentorship, as Finnish mentors pointed out. They felt that the lack of support and co-operation with school and teachers was a main problem that caused inadequacy. Furthermore, they claimed that teachers and mentors had different viewpoints of student mentorship and no agreement upon the provision of equal mentorship. Finnish mentors also stated that students' theoretical competences were not on an appropriate level, because they had not enough theoretical studies before practice. In addition, Finnish mentors argued that student evaluation forms from schools were difficult to use. British mentors expressed a similar conception, who considered evaluation criteria unclear and unrealistic to attain. Moreover, they felt that current nursing clinical education in placements and students' learning objectives for clinical practice were unrealistic.

The evaluation forms are difficult (Finnish mentor) and criteria at too high a level (British mentor)

Students' training is completely different to reality. (British mentor)

There are not enough theoretical lessons in the school; students have to learn so much in practice. We received too little information from the school. (Finnish mentor)

\subsubsection{Insufficient personal resources and versatile skills of mentors}

The main limitation in student mentorship that both Finnish and British mentors expressed was the deficiency of enough protected time to mentor students. Moreover, both Finnish and British mentors felt that the lack of extra personal remunerations was also a restriction in the current mentorship. Finnish mentors required some free time from work for having the opportunity to benchmark in other organisations as well as the possibility to participate in a mentor preparation programme. They felt the inadequate mentorship lacked any kind of support to mentors, and they did not have any personal benefits. Moreover, mentors had difficulties to organise the same shifts with students and no time during their shifts to write students' final assessment. British mentors felt that they have too many responsibilities at the same time, e.g. patients and students, and they have work pressure. They were afraid that this could influence students' adoption of some inadequate habits. Furthermore, they argued that there were different insights and performances of student mentorship, because nurses have educated and trained themselves in different times and ways. These could illustrate mentorship's insufficiency.

We have no benefits from mentorship. We have to participate in mentor education in our own free time. (Finnish mentor)

You are expected to teach important skills and at the same time deliver high quality patient care. (British mentor)

\subsection{I mprovement-requiring mentorship}

\subsubsection{Heightening status and creating systematic guidelines}

Finnish mentors required unified national guidelines for student mentorship and flexible educational possibilities. They also wished that organisational procedures would develop student mentorship; give more appreciation to student mentorship and improve clinical teachers' supportive role. Furthermore, they emphasised that the rewarding and feedback system of student mentorship should be more systematic. In addition, British mentors suggested that the mentor's role 
should be voluntary. They also felt that standards for student mentorship are necessary to be kept available also in the future. Moreover, they stated that the criteria for evaluation of students should be made clear.

At the national level, student mentorship should be similar. We need education, knowledge, appreciation and financial reward for student mentorship. (Finnish mentor)

Being able to have a voluntary mentor role and keeping standards for the future. (British mentor)

\subsubsection{I ncreasing collegial involvement and placement allocation}

Only Finnish mentors presented placement procedures for developing student mentorship. They required more collegial support and benchmarking and networking with other placements in other organisations within student mentorship. Moreover, they hoped that placements' limitations and the durations of clinical practice periods should be taken into account and planned more carefully.

We should network with other colleagues so that we know them better and we don't have to create all things by ourselves. We need opportunities to benchmark other placements. (Finnish mentor)

When there are, for example, some large projects in placement, it is not worth taking students at that time. (Finnish mentor)

\subsubsection{Enhancing educational procedures and students' preparedness}

Finnish mentors expected more support, co-operation and face-to-face partnership with educational stakeholders. For example, they required mentorship education or educational days from the university and more support and feedback from lecturers regarding student mentoring. On the other hand, British mentors expected realistic objectives for students' clinical practice and students' own responsibility and willingness to learn. Additionally, Finnish mentors highlighted that students should have more skill labs or clinical laboratory hours in school before coming to placements, more clinical placements in total education and longer periods for practicing in placements. They felt that clear criteria of competences need to be achieved by students and these competences have to be determined. Students had to have theoretical sessions or educational hours in placements, but they should not have too many written tasks during the practice period. They also argued that students have to be prepared better to practice so that they commit to their clinical learning and placement.

We need more cooperation with teachers, and students' better preparedness to practice period and having not so much learning tasks. (Finnish mentor)

Students need to be responsible for their own learning, it depends on their enthusiasm. (British mentor)

\subsubsection{Obtaining personal feedback, further education and feel of enthusiasm}

Finnish mentors desired to obtain some improvements in their educational and personal resources in order to provide effective student mentorship. They presented the personal needs for additional education; mentor preparation programmes and theoretical studies, such as expert lessons with evidence-based knowledge. They also required more assessment on their mentoring, in the form of both positive and constructive feedback from students. British mentors highlighted that there was a need to clarify each nurse's own personal capacity, attitude and willingness to be a mentor.

It is important to get more personal feedback and more support from management, and also theoretical education and actual evidence-based knowledge. (Finnish mentor)

It is framework, because not everyone is going to enjoy being a mentor. (British mentor) 


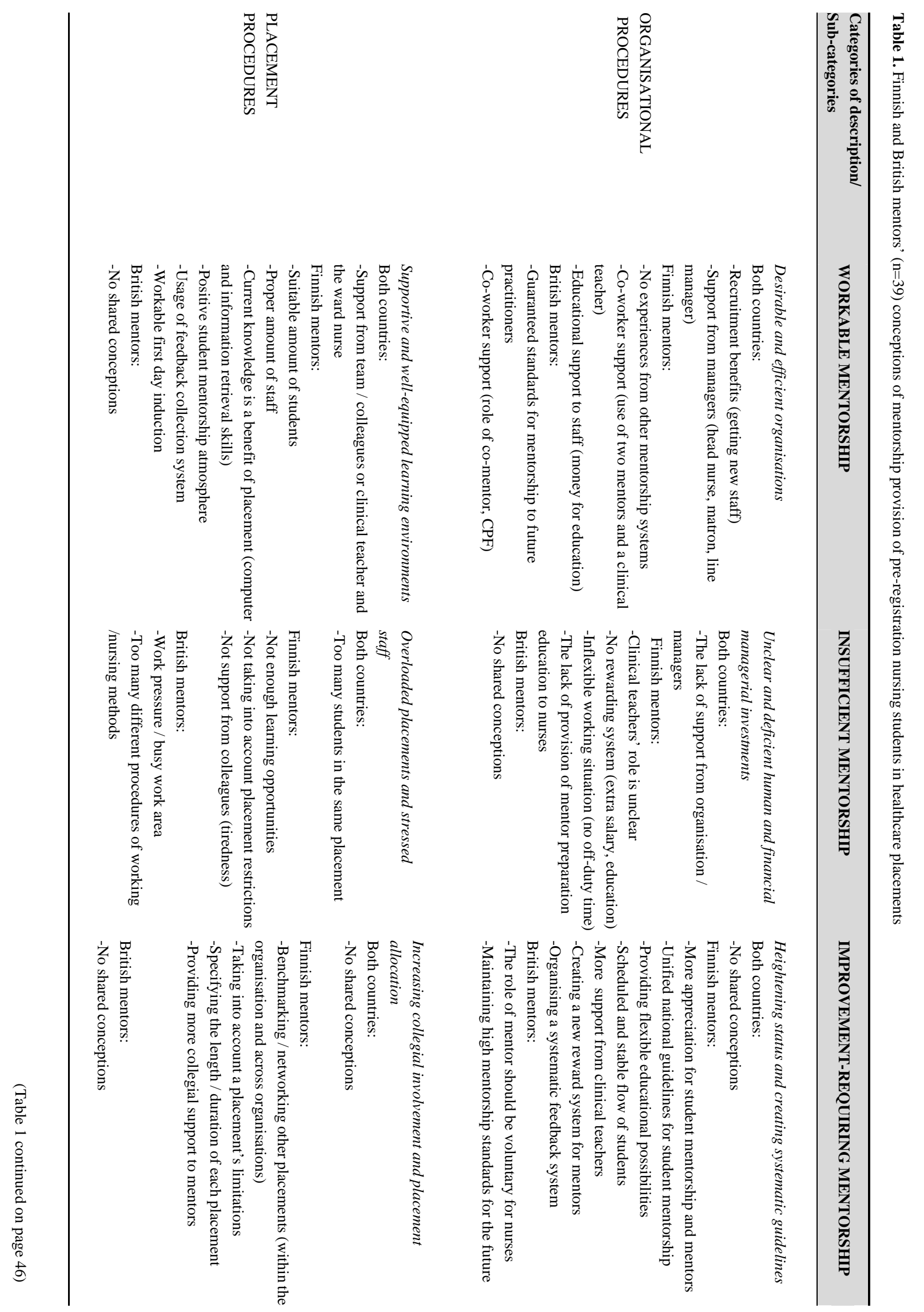









\section{Discussion}

\subsection{Limitations of the study}

The use of focus groups as the data collection method might limit the achievement of all the possible variation of the ways in which mentors experienced the phenomenon of mentorship. This could occur because of group effect ${ }^{18}$, which might hinder some mentors' expression. Nevertheless, it is also possible that discussion within the group could encourage some members to express their views more openly and clearly than possible at individual level ${ }^{[21]}$. In this study the atmosphere in focus groups was found flexible and the participants expressed their views openly. The mentors' conceptions in this qualitative study cannot be generalised, because of the small group involved. However, the results may be transferable to similar mentorship provision in healthcare settings.

\subsection{The current mentorship provision for student nurses}

The findings of this study showed mentors' conceptions of provision of current mentorship for pre-registration nursing students in the context of Finnish and British clinical nursing education. Finnish mentors have several positive and negative arguments in the dimensions of organisational, environmental, educational and personal procedures. These oppose many of the British mentors' expressions, which focused mostly on their personal and educational procedures. Mentors from both countries felt that mentorship worked well when the managerial and collegial support is available, but findings also pointed out the lack of management involvement in student mentorship. However, it has been argued that leadership is a one part in developing students' learning in placement ${ }^{[3]}$.

In the UK British mentors' conceptions indicated that pre-registration nursing students' mentorship seems to be quite well-organised and placements were supportive and well-equipped. They emphasised only mentors' work pressure and need for maintain the accepted standards for students' clinical education and mentorship. Yet in Finland, there were lots of issues that need development in student mentorship, such as having national guidelines, adequate resources and support, more joint activities with teachers and unified mentor preparation programme. Also, it has been presented that confusion and a lack of preparation for the role of mentor was seen as a barrier to students' mentorship ${ }^{[22]}$. In addition, the recommendations have been expressed that the current healthcare placements have to pay more attention to student mentorship. For example, it is necessary to offer extra time or other benefits to mentors, because educational institutions do not have much impact on staff situation in clinical placements ${ }^{[16]}$.

Both Finnish and British mentors' conceptions showed that supportive partnership with educators is important to ensure a well-working student mentorship. However, there was still a gap between work life and education. Especially in Finland, there is a need for improvements of partnership with education. For example, with co-operation, it is possible to assure students' theoretical preparedness and motivation to conduct clinical practice. Furthermore, mentors from both countries considered the assessment of students challenging depending on, for example, the difficulties to use of the evaluation forms and criteria. Corroborating this observation is the finding that the lack of consistency in evaluation documents creates a barrier to student placement learning ${ }^{[22]}$. Therefore, closer co-operation with clinical and educational stakeholders to plan and work together and develop the assessment of students is necessary in order to provide also competent workforce to the future. This suggestion is mentioned also in new NMC standards for nursing education ${ }^{1}$. Furthermore, combined educational days and workshops could be one opportunity to develop unified viewpoints for the provision of student mentorship. This kind of collaboration is needed not only in national area but also between countries in order to forward the unification process. Furthermore, British mentors worried about the inconsistency of goals of clinical practice in relation to the reality of nursing. Similar concerns have been presented earlier, and these concerns depended on the academic faculty's vague understanding of placements as students' learning environments ${ }^{[6]}$.

Moreover, Finnish mentors required benchmarking and collegial collaboration with other nursing organisations in order to see different procedures and to obtain new insights into the provision of student mentorship. Similarly, it has been 
highlighted the ability of organisations to work together among placements in a truly collaborative way ${ }^{[22]}$. Moreover, increased contacts and communication between educators and mentors have been requested ${ }^{[16]}$. The suggestion to use web-based methods could also increase the connection of mentors to each other. However, the findings did not show totally new approach for the provision of student mentorship or for unifying the insights of mentorship. The one-to-one mentorship was preferred, and was seen as a common procedure in mentor-student relationship ${ }^{[17]}$. Nevertheless, mentors were not fully confident in current mentorship procedures ${ }^{[16]}$. Therefore they recognised the importance of clinical education which cannot be underestimated.

Notably, the provision of current student mentorship affected positively the mentors' professional development, as both Finnish and British mentors agreed. On the other hand, the lack of protected time for mentorship decreases mentors' possibilities to provide effective mentorship, which was also considered in the previous studies ${ }^{[14,16,17]}$. The positive status of the mentor's role is necessary for guaranteeing consistent mentorship. British mentors highlighted that the role of mentor should be voluntary for a nurse. In addition, the role of the mentor needs to be reformed, strengthened and supported ${ }^{[10]}$. On the other hand, it has been demanded the clarity in different roles in clinical placements in order to decrease the confusion amongst stakeholders ${ }^{[11]}$.

\section{Conclusion}

It is important to clarify the provision of student mentorship. This clarification can increase the quality of placement learning. The current mentorship provision for pre-registration student nurses requires further systematic development. Especially in Finland, where there is a need for national guidelines for student mentorship and mentor education. The challenge for development of mentorship provision of students lies within the collaboration of nursing educators and healthcare placements' providers. Therefore, nursing organisations and placements, and higher education institutions need to have a clear, co-operative mentorship strategy for pre-registration nursing students. Intense partnership benefits educational and clinical stakeholders to develop unified approach to students' mentorship and also clarify and renew the role of mentor. In addition, benchmarking different placements and their mentorship provision are necessary in order to reform student mentorship and develop its unification. Thus, highly valued, systematic and collaborative well-working student mentorship is one option for creating positive working environment and also for the recruitment of new staff to nursing organisations. It will also help to unify clinical education across European countries. However, further studies are needed from student mentorship in pre-registration education in Europe to continue the unifying process.

\section{Conflict of interest}

No conflict of interest has been declared by the authors.

\section{Funding}

This study as a part of the Finnish-British research project has received a grant from the Finnish Foundation of Nursing Education. The corresponding researcher has also supported by a personal grand for University of Eastern Finland (formerly University of Kuopio).

\section{Acknowledgement}

We would like to thank the Finnish Foundation of Nursing Education for giving a grant to the research project and the University of Eastern Finland (formerly University of Kuopio) for giving a PhD grant to the corresponding researcher, which made this study possible.

\section{Authorship credit}

Conception and design: MJ, DJ, KT, HT; data collection MJ, DJ, HT; data analysis MJ, KT, HT; manuscript drafting: MJ, DJ, KT, HT; final version approving MJ, HT, KT, DJ 


\section{References}

[1] Nursing and Midwifery Council (NMC). Standards for pre-registration nursing education [Internet]. United Kingdom, London, 2010. Available from: http://standards.nmc-uk.org/PublishedDocuments/Standards\%20for\%20pre-registration\%20nursing\%20education\%2016082010.pdf. (9 February 2011 accessed)

[2] Salminen L, Stolt M, Saarikoski M, Suikkala A, Vaartio H and Leino-Kilpi H. Future challenges for nursing education - A European perspective. Nurse Education Today. 2010; 30: 233-238. http://dx.doi.org/10.1016/j.nedt.2009.11.004

[3] Saarikoski M, Marrow C, Abreu W, Riklikiene O and Ozbicakci S. Student nurses' experience of supervision and Mentorship in clinical practice: A cross cultural perspective. Nurse Education in Practice. 2007; 7: 407-415. http://dx.doi.org/10.1016/j.nepr.2007.02.006

[4] European Council. EC Directive 2005/36/EC of the European Parliament and of the Council of 7 September 2005 on the recognition of professional qualifications. Official Journal of the European Union (L255 /22 -30 September 2005), 2005.

[5] The Finnish Ministry of Social Affairs and Health. Increasing the effectiveness and attraction of nursing care by means of management. An action plan for the years 2009-2011. Publications of Ministry of Social Affairs and Health 2009:18 in Finland, 2009. (in Finnish)

[6] Mattila L-R, Pitkäjärvi M and Eriksson E. International student nurses' experiences of clinical practice in the Finnish health care system. Nurse Education in Practice. 2010; 10: 153-157. http://dx.doi.org/10.1016/j.nepr.2009.05.009

[7] Taylor J, Irvine F, Bradbury-Jones C and McKenna H. On the precipice of great things: The current state of UK nurse education. Nurse Education Today. 2010; 30: 239-244. http://dx.doi.org/10.1016/j.nedt.2009.10.013

[8] Warne T, Johansson U-B, Papastavrou E, Tichelaar E, Tomietto M, Van den Bossche K, Moreno MFV and Saarikoski M. An exploration of the clinical learning experience of nursing students in nine European countries. Nurse Education Today. 2010; 30: 809-815. http://dx.doi.org/10.1016/j.nedt.2010.03.003

[9] Nursing and Midwifery Council (NMC). Standards to support learning and assessment in practice. NMC standards for mentors, practice teachers and teachers. United Kingdom: London, NMC, 2008.

[10] Papastavrou E, Lambrinou E, Tsangari H, Saarikoski M and Leino-Kilpi H. Student nurses experience of learning in the clinical environment. Nurse Education in Practice. 2010; 10: 176-182. http://dx.doi.org/10.1016/j.nepr.2009.07.003

[11] Murray SC and Williamson GR. Managing capacity issues in clinical placements for pre-registration nurses. Journal of Clinical Nursing. 2009; 18: 3146-3154. http://dx.doi.org/10.1111/j.1365-2702.2008.02693.x

[12] Edgecombe K and Bowden M. The ongoing search for best practice in clinical teaching and learning: A model of nursing students' evolution to proficient novice registered nurses. Nurse Education in Practice. 2008; 9: 91-101. PMid:19058758 http://dx.doi.org/10.1016/j.nepr.2008.10.006

[13] Levett-Jones T and Lathlean J. Belongingness: A prerequisite for nursing students' clinical learning. Nurse Education in Practice. 2008; 8: 103-111. http://dx.doi.org/10.1016/j.nepr.2007.04.003

[14] Myall M, Levett-Jones T and Lathlean J. Mentorship in contemporary practice: the experiences of nursing students and practice mentors. Journal of Clinical Nursing. 2008; 17: 1834-1842. http://dx.doi.org/10.1111/j.1365-2702.2007.02233.x

[15] Ali PA and Panther W. Professional development and the role of mentorship. Nursing Standard. 2008; 22: 35-39. PMid:18649718

[16] Heale R, Mossey S, Lafoley B and Gorham R. Identification of facilitators and barriers to the role of a mentor in the clinical setting. Journal of Interprofessional Care. 2009; 23: 369-379. http://dx.doi.org/10.1080/13561820902892871

[17] Croxon L and Maginnis C. Evaluation of clinical teaching models for nursing practice. Nurse Education in Practice. 2009 ; 9: $236-243$. http://dx.doi.org/10.1016/j.nepr.2008.06.004

[18] Curtis E and Redmond R. Focus groups in nursing research. Nurse Researcher. 2007; 14: 25-39. PMid:17315777

[19] Marton F. Phenomenography. In The International Encyclopedia of Education, Pergamon. T. Husén and TN. Postlethwaite, second ed. Göteborg: Göteborg University. 1994; 4424-4429. http://www.ped.gu.se/biorn/phgraph/civil/main/1res.appr.html. (10 February 2009 accessed).

[20] Sjöström B and Dahlgren LO. Applying phenomenography in nursing research. Journal of Advanced Nursing. 2002; 40: $339-345$. PMid:12383185 http://dx.doi.org/10.1046/j.1365-2648.2002.02375.x

[21] Burns N and Grove SK. The practice of nursing research: appraisal, synthesis and generation of evidence. Sixth ed. Missouri: Saunders Elsevier Inc., 2009.

[22] Barnett T, Cross M, Jacob E, Shahwan-Akl L, Welch A, Caldwell A and Berry R. Building capacity for the clinical placement of nursing students. Collegian. 2008; 15: 55-61. http://dx.doi.org/10.1016/j.colegn.2008.02.002 